\title{
Sobre como é ainda possível filosofar
}

\author{
On how it is still possible to philosophize
}

\section{Resumo}

O artigo retoma o pensamento filosófico de Sergio Fernandes a partir da experiência da autora, enquanto sua ouvinte e leitora. Ressalta as influências de Sergio na sua formação e em suas próprias pesquisas. São revisadas a noção de Consciência e a Filosofia da Religião de Sergio, com ênfase no chamado 'problema da autorreferência', entendido como um fio condutor da Ontologia e da Ética de Fernandes. O pensamento aqui delineado se revela, sobretudo, extremamente potente para a reflexão filosófica nos dias atuais.

Palavras-chave: Sergio Fernandes; Filosofia; Consciência; Religião; Autorreferência.

\section{Abstract}

The article retakes the philosophical thought of Sergio Fernandes from the authoress experience, while her listener and reader. The text thus highlights the influence of Sergio in her formation and in her own research. Thereby, the notions of Conscience and the Philosophy of Religion of Sergio are reviewed, with emphasis on the so-called 'problem of self-reference', understood as a thread of the Ontology and the Ethics of Fernandes. In this way, the thought explained here proves extremely powerful for philosophical reflection today.

Keywords: Sergio Fernandes; Philosophy; Consciousness; Religion; Self-reference.

\footnotetext{
* Doutora em Filosofia pela PUC-Rio. Professora da Universidade do Estado do Rio de Janeiro. E-mail: camilajourdan@gmail.com.
}

Recebido em: 14/02/2019. Aceito em: 16/07/2019. 


\section{Introdução}

Conheci Sergio Fernandes ainda adolescente, antes de entrar para a faculdade. Eu ainda cursava o Ensino Médio, mas já pretendia estudar Filosofia no Ensino Superior. Ele me foi apresentado por Leandro Chevitarese, meu primeiro professor de Filosofia, como sendo um filósofo. Jamais esqueci suas palavras para mim no dia em que fomos apresentados, oraculares: "você tem talento para a Filosofia, mas terá sérios problemas com as autoridades". Palavras proféticas. Nada havia sido dito por mim até aquele momento que permitisse tal conclusão. Sergio não procurou se justificar, eu também não busquei justificativas. Durante toda a minha formação sempre foi como um Filósofo que eu o vi, muito mais que como um professor, alguém que vivia a Filosofia de maneira plena. Na Academia, poucas pessoas conheci que ousaram pensar por elas mesmas e enfrentar diretamente o produtivismo acadêmico que nos submete, como sendo verdadeiramente antifilosófico. No mais das vezes, somos ensinados a aceitar isso para sobrevivermos e a não nos aproximarmos demais de Sofia, mesmo que isso acabe fazendo com que a nossa atividade perca totalmente o sentido. Sergio foi um dos poucos que pelo exemplo me ensinou a voar por sobre os textos, tecer hipóteses além das interpretativas, fazer Filosofia apesar da Academia (nunca por causa dela), pensar-com os pensadores em vez de pensar somente pelo texto ou pelo autor. Infelizmente, como não poderia deixar de ser, ele foi punido por isso. Acabou tendo também seus problemas com as autoridades. É sempre um pouco de nós mesmos o que melhor percebemos nos outros. É sempre uma condenação o que espera aqueles que ousam desafiar os mecanismos de sujeição que tornam hoje a Filosofia cada vez mais domesticada. E as condenações assumem também formas bastante distintas. Sergio foi um exemplo, para mim, de sabedoria e de subversão. Suas aulas condicionaram minhas escolhas e reflexões filosóficas em tantos aspectos que seria difícil resumir tudo em um pequeno artigo. O objetivo deste texto é repassar essa influência em alguns elementos que me são mais evidentes, aqueles que nunca esqueci. É um pouco o que eu gostaria de ensinar às pessoas sobre a Filosofia do Sérgio. Nesse sentido, eu sublinho aquilo que me parece mais importante e não tenho pretensão de ser totalmente fiel aos seus pormenores. O importante de um filósofo é que ele leve outras pessoas a pensar com ele, mas nunca que lhes poupe o trabalho de pensar por elas mesmas. De qualquer forma, em grande medida, o presente texto serve como uma pequena introdução a alguns elementos do pensamento deste Filósofo com quem tive a oportunidade feliz de estudar. 


\section{A consciência e a autorreferência}

A questão que primariamente influenciou minha formação no pensamento do Sergio foi a questão da autorreferência. Sergio chega à questão da autorreferência pensando a estrutura da consciência, que deveria tomar a si mesma como objeto. A influência pode ser assumidamente hegeliana, mas as análises e conclusões desenvolvidas por Sergio se diferenciam bastante da dialética, sobretudo porque rejeitam explicitamente a ideia de uma síntese final. Ora, como a autorreferência seria impossível, a consciência deveria ser entendida como uma tela transparente através da qual conhecemos o mundo. Como ainda aparece em Deus: a experiência do ser humano:

[A Consciência] é pura luz, sem coisa alguma que a reflita, de modo que é invisivel. É como uma vidraça perfeitamente transparente e perfeitamente limpa. Se alguma coisa refletir essa luz, ou seja, se a vidraça estiver suja, a mente projeta essa coisa como objeto da intencionalidade, e a vidraça recua, inalterável, sempre perfeitamente transparente. ${ }^{1}$

Haveria sempre algo que não poderia ser olhado, pois seria através do que olhamos. Ou ainda, usando a formulação metafórica que Fernandes gostava: "uma cobra não poderia comer o próprio rabo, pois não vai conseguir jamais comer a sua própria boca". Nesse sentido, o autoconhecimento, supondo a autorreferência, é impossível. Aquilo que conhece não pode conhecer justamente aquilo a partir do que conhece. Esta parece ser uma questão fundamental para toda a Filosofia. Tentar mirar o que usamos para mirar com isso mesmo que usamos ou explicar aquilo que utilizamos para explicar seria um limite cognitivo fundamental, uma falta de critérios da qual não se consegue escapar em toda a história do pensamento, já que qualquer afirmação absoluta, que tente dar conta de tudo, pressupõe a si mesma, isto é, inclui-se no tudo de que tenta dar conta. Como a Filosofia trabalha com ontologias condena-se às afirmações que se autopressupõem. Parece, assim, que em algum momento será necessária uma superação da dualidade sujeito-objeto do conhecimento, ou seja, será necessário um acesso direto à realidade. A Filosofia não teria como manter um questionamento infinito de pressupostos sem "dobrar-se sobre si mesma", portanto, em algum momento, a Filosofia

$1 \mathrm{O}$ artigo Deus: a experiência do ser humano encontra-se publicado postumamente na presente edição da Revista O que nos faz pensar PUC-Rio. 
terá que ter uma postura dogmática ou comprometer-se com uma experiência mística, uma verdade vivida. Essa é a proposta de Fernandes, em Filosofia e Consciência (1995), já aqui apontando para um limite da representatividade. Com isso, podemos também traçar paralelos e chegar facilmente da formulação de Fernandes a algumas formulações do Tractatus, de Wittgenstein, caminho que resume em grande medida o percurso intelectual que animou minha formação ${ }^{2}$ :

\subsection{O sujeito que pensa representa, não existe.}

Se eu escrevesse um livro O Mundo tal como o Encontro, nele teria que incluir também um relato sobre meu corpo, e dizer quais membros se submetem à minha vontade e quais não, etc. - este é bem um método para isolar o sujeito, ou melhor, para mostrar que, num sentido importante, não há sujeito algum: só dele não se poderia falar neste livro.

5.632 O sujeito não pertence ao mundo, mas é um limite do mundo.

5.633 Onde no mundo se há de notar um sujeito metafísico? Você diz que tudo se passa aqui como no caso do olho e do campo visual. Mas o olho você realmente não vê. E nada no campo visual permite concluir que é visto a partir de um olho.

\subsection{Pois o campo visual não tem uma forma como esta:}

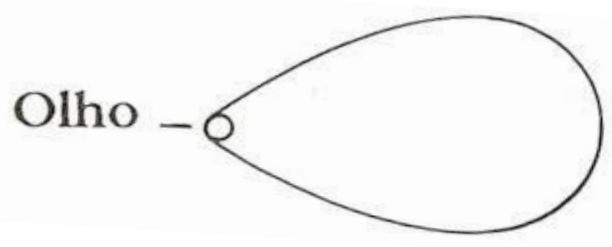

2 Esta associação é de responsabilidade inteiramente minha. Sergio, por outro lado, considerava Wittgenstein um contrafilósofo (o que, aliás, não teria sido ofensivo a Wittgenstein, que passou toda sua vida tentando se livrar da Filosofia sem conseguir, razão pela qual esta afirmação, apesar de não ser ofensiva, não é muito justa). Em seu trabalho inédito Sergio afirmou: "O primeiro [Wittgenstein], levando às últimas consequências a má compreensão da Mente, do Pensamento e da Linguagem, afirmou que sobre aquilo que não podemos (?) falar devemos (?) calar - como se não fosse justamente aí, que se torna interessante falar!" E, certamente, Wittgenstein no Tractatus também concorda que isso, sobre o que não se pode falar, é o mais importante. Apenas para ilustrar tal concordância, selecionamos as seguintes passagens do Tractatus: 6.41. O sentido do mundo deve estar fora dele. No mundo, tudo é como é e tudo acontece como acontece; não há nele nenhum valor - e se houvesse, não teria nenhum valor. (...) 6.42 É por isso que tampouco pode haver proposições na ética. Proposições não podem exprimir nada de mais alto. (...) 6.4311 A morte não é um evento da vida. A morte não se vive. Se por eternidade não se entende a duração temporal infinita, mas a atemporalidade, então vive eternamente quem vive no presente. Nossa vida é sem fim como nosso campo visual é sem limite. (...) 6.522 Há por certo o inefável. Isso se mostra, é o Místico. 
Quem conhece um pouco da história do Programa Logicista sabe como os paradoxos por autorreferência foram centrais no período inicial da Filosofia Analítica, tendo condicionado o desenvolvimento da Teoria do Tipos, de Russell, e sendo a razão do se voltar mesmo de Wittgenstein para a Filosofia3. A questão da autorreferência no fundamento da linguagem, da necessidade e das determinações semânticas acompanhou toda a Filosofia do pensador austríaco. Apenas para ilustrar com uma citação da última fase do autor:

Mas a fundamentação, a justificação da evidência, tem um fim - mas o fim não é um fato, certas proposições que se apresentam como verdadeiras, isto é, não se trata de um ver da nossa parte, é o nosso agir o que está no fundo dos nossos jogos de linguagem. (DC, 204)

A autorreferência aponta-nos a necessidade de algo (e a designação desse algo como 'a mística' também foi a aposta do Tractatus) que vá para além do discurso lógico/representativo, já que a cobra não pode se comer para legitimar nosso saber, linguagem, pensamento e cognição. Na Filosofia de Fernandes, isso acabou significando uma diferenciação entre a Mente e a Consciência, tratando-se a primeira como inconsciente e determinada biossocialmente, enquanto a Consciência seria transferida para o âmbito do Ser. Neste sentido, a Mente seria um efeito inconsciente da Consciência, efeito este que carregaria a opacidade necessária, a dicotomia sombra/luz necessária, ou ainda, as dualidades necessárias a tudo aquilo que chamamos nosso âmbito da experiência sujeito-objeto'.

\section{O ser o e existir}

Em seu livro Ser Humano: Um ensaio em Antropologia Filosófica (2005), Fernandes defende uma Antropologia Filosófica que é ao mesmo tempo uma contribuição para a Filosofia da Religião. A teoria de Fernandes propõe que o ser humano é uma experiência divina. Ela parte da separação radical entre Ser e existir: o que existe não É e o que É não existe. Não podemos experimentar o que Somos enquanto Somos e não podemos Ser aquilo que experimentamos. É a separação entre Ser e existir que permite a experimentação. Esse

3 Esta leitura foi sustentada em minha tese de doutorado: "Impredicatividade, Generalidade e o Desenvolvimento do Pensamento de Wittgenstein", defendida em 2009 pelo Programa de Pós-Graduação em Filosofia da PUC-Rio. 
é, de fato, o mesmo problema epistemológico enfocado por Fernandes em Filosofia e Consciência (Conf.: 1995, pp.73-203). Trata-se aqui do problema da separação sujeito-objeto: para conhecermos algo não podemos Ser aquilo que pretendemos conhecer. Por isso nunca conhecemos algo completamente, justamente porque a autorreferência é impossível. Como já notamos, o conhecimento pressupõe um sujeito que olha e que não pode ser olhado enquanto olha.

Para Fernandes, Deus seria o Ser em si ou a consciência em si, que não pode visar a si mesma. O ser humano seria sua experiência, ou melhor, seria Deus enquanto experiência. Vontade impossível que Deus tem de conhecer a si mesmo, seria humana essa tentativa trágica de se autoconhecer. Deus não pode tomar-se como objeto, pois não pode pensar em si mesmo sem tornar-se outro: aquele que pensa e o que é pensado. Esse outro é, portanto, o ser humano, o pensamento de Deus. É essa dualidade entre sujeito e objeto, necessária à experimentação que, segundo Fernandes, imprime o abismo intransponível entre Ser e existir. Mas, se o existir separa, Deus reúne: "O que está separado só se reúne quando nos lembramos de que somos Deus, enquanto Experiência, ou seja, somos Experiências de Deus. Até que nossa Mente se abra e esta lembrança se torne presente à nossa Experiência, só há, em última análise, sofrimento."

A separação entre Ser e existir não é nenhuma novidade filosófica. De acordo com Sergio, teria sido Aristóteles o principal responsável pela redução ocidental do Ser ao existir, isto é, o tratamento do Ser como o existente. A originalidade do pensamento de Fernandes está no enfoque dado para essa separação. Para ele, o Ser não está no tempo. O que permanece, o que pode ser identificado no tempo como idêntico a si mesmo é o ente. Já o Ser é aquilo que É. Nada poderia ser dito sobre ele sem que se tornasse existente, ou seja, sem que o mencionado abismo entre Ser e existir viesse a ser. Em certo sentido, Sergio parece levar às últimas consequências a noção clássica de Ser. Ou seja, o Ser seria algo único, um evento que não muda no tempo, tão permanente que completamente impermanente ou tão impermanente que completamente permanente. Nós só consideramos que algo se move, pois consideramos que algo nele permaneceu. O movimento absoluto seria equivalente a um momento único. E, por ser único, não poderia ser idêntico a si mesmo, já que a noção de identidade estaria diretamente relacionada com as

4 Do artigo: Deus: a experiência do ser humano, publicado postumamente na presente edição da Revista $\mathrm{O}$ que nos faz pensar, PUC-Rio. 
dualidades constitutivas do pensamento e da linguagem. Para explicar este ponto Fernandes argumenta que para dizermos que 'a é igual a A' seria preciso haver um terceiro termo que os igualasse, isto é, $A=A$ ' se e somente se $A=B$ e A'=B. A noção de identidade, assim, só faria sentido por projetar esse B na existência. E seria, portanto, somente na existência temporal que a identidade poderia ser afirmada. Dito de outro modo: somente onde as coisas não são, duas coisas podem ser identificadas a uma e uma coisa pode ser identificada a duas. Só o que pode ser tomado como o mesmo de maneira diferente pode se repetir. As maneiras mesmas, ou seja, os indivíduos, seriam únicos, não se repetiriam. Assim, conclui Fernandes, toda vez que identificamos algo a outro estamos separando-os mais do que os unindo (Conf.: FERNANDES, 2005, p.116).

O pensamento seria uma parte da estrutura da existência que permitiria a experiência da duração temporal. Nos termos de Fernandes, o pensamento seria como um 'projetor'. Assim como a própria experiência não pode ser experienciada e a mudança não muda, o Ser, enquanto Ser, não pode ser pensado, precisa ser compreendido. E na compreensão não haveria separação entre sujeito e objeto. Os nossos conceitos seriam formados justamente por esse algo que permanece na identificação e, por isso, os conceitos pertencem à existência. Só é possível pensar o que existe, nunca o que É. A existência permite o pensamento e o pensamento permite a existência. Isso se explica porque, como vimos, é por Deus tentar pensar a si próprio - só havia Ser, ele não poderia pensar outra coisa - que a existência vem a ser. Sempre que há pensamento, há existência, isto é, há todo o dualismo próprio à representação: o que pensa e o que é pensado. Mas o próprio pensar é único. Ser e pensar estão, para Fernandes, em uma relação de bicondicionalidade, são condições necessárias e suficientes um para o outro. O que significa que são equivalentes. Podemos sempre apenas nos referir ao Ser, por oposição ao existir, como algo momentâneo e único.

A conclusão é que nós somos Deus enquanto experiência. Quando nos identificamos com o não-ser da existência, ou seja, com o experienciador (aquele que permanece no tempo) estamos cometendo um equívoco. O Ser em si é a Consciência, o ser humano é a sua experiência. No entanto, todos os dois São; portanto, não podem ser experienciados ou ditos como permanentes no tempo. São, mas não existem. O que existe é uma (pseudo) consciência e uma (pseudo) experiência intencional (o não-ser), que projetam objetos para fora de si, entre eles, o próprio 'eu' (então definido como a alienação do Ser). A separação entre Ser e existir e a consequente projeção do 'eu' 
são condições de possibilidade da intencionalidade, mas não da experiência mística da compreensão. Na compreensão, não haveria mais separação entre aquele que compreende e o que é compreendido (o sujeito e o objeto), não haveria mais permanência no tempo e não haveria, portanto, mais existência. A diferença entre nós e Deus seria a diferença entre criador e criatura. Somos sua experiência e somos também criadores. Deus e ser humano são, portanto, indissociáveis. Embora haja necessariamente entre eles uma identidade e uma distinção, uma unidade e uma separação.

Sergio diferencia então experiência da vida de vida da experiência. A primeira diria respeito à existência, à permanência temporal, à separação sujeito/objeto (conhecimento) e a todos os pares de dicotomias constitutivos da mente, linguagem e cognição. A segunda diria respeito ao Ser, ao momento único, à mítica união sujeito-objeto característica da compreensão. Esses dois aspectos seriam, ao mesmo tempo, excludentes e complementares. Para Fernandes, essa dualidade não pode ser reduzida, como propunha a dialética, a um terceiro termo sintético. Seus termos são, como dissemos, indissociáveis e complementares.

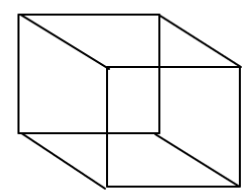

A imagem do cubo é a figura que Sergio usa para expressar essa ideia: a dualidade em questão é entre forma e fundo. Percebemos ora a forma que era fundo sobre o fundo que era forma, ora o fundo que era forma sobre a forma que era fundo. Vemos as duas figuras alternadamente, mas existe uma dimensão que esses termos compartilham: a dimensão da profundidade. Essa seria a dimensão sagrada da experiência religiosa, associada por Sergio à área filosófica da Estética.

Sergio distingue três dimensões na experiência religiosa e associa essas dimensões às dimensões da figura do sólido supracitado. Qualquer exagero de uma delas desfaz o sólido. O filósofo relaciona ainda para cada uma das dimensões uma área filosófica, categorias (que seriam ativas) e intuições sensíveis (passivas). Além disso, estabelece as condições de possibilidade de cada uma delas, formando a seguinte tabela: 


\begin{tabular}{|c|c|c|}
\hline ÁREAS FILOSÓFICAS & DIMENSÕES & CATEGORIAS \\
\hline $\begin{array}{c}\text { Ontologia (Ser) } \\
\text { Mística (caminho) } \\
\text { Meio }\end{array}$ & Mistério \\
\hline $\begin{array}{c}\text { Epistemologia } \\
\text { conhecer) }\end{array}$ & $\begin{array}{c}\text { Profética (verdade) } \\
\text { Mensagem }\end{array}$ & Segredo \\
\hline Estética (experienciar) & $\begin{array}{c}\text { Sagrada (vida) Meio é } \\
\text { a mensagem }\end{array}$ & Arcano \\
\hline
\end{tabular}

\begin{tabular}{|c|c|c|}
\hline INTUIÇÕES & $\begin{array}{c}\text { CONDIÇÕES DE } \\
\text { POSSIBILIDADE }\end{array}$ & $\begin{array}{c}\text { ANALOGIAS NO } \\
\text { SÓLIDO }\end{array}$ \\
\hline $\begin{array}{c}\text { União } \\
\text { Intuição tátil }\end{array}$ & Transparência & Altura \\
\hline $\begin{array}{c}\text { Contemplação } \\
\text { Intuição auditiva }\end{array}$ & Silêncio & Largura \\
\hline $\begin{array}{c}\text { Ação } \\
\text { Intuição visual }\end{array}$ & Criação & Profundidade \\
\hline
\end{tabular}

A Estética seria a experiência em si mesma, pois não divide a experiência em experienciador e experienciado, ou seja, em sujeito e objeto. Ela é a profundidade compartilhada pelos termos da contradição. Na estética, o meio é mensagem. Essa dimensão Sagrada seria a realização suprema e definitiva e, portanto, é a dimensão a que a teoria de Fernandes dá principal enfoque. Para caracterizá-la, Sergio utiliza inclusive a famosa expressão "a vida como obra de arte".

A dimensão mística seria divina, o Ser em si mesmo, a experiência pura, a união completa e indizível, o Uno primordial, o excesso de luz que não permite ver, pois não possui o contraste da existência. É simbolicamente o sol. Já a dimensão profética é humana, é criação, tem conteúdo, pode ser conhecida, pertence à existência e à separação. Simbolicamente é a lua, ou melhor, o sol da meia-noite. É experiência religiosa, pois requer o silêncio como condição 
de possibilidade para se ouvir e não teria relação com disputas entre teorias. Embora nessa dimensão não exista a perda de sujeito que há na união mística com a verdade, na dimensão profética, afirma Fernandes, seria preciso 'bater à porta e sussurrar segredos'. A dimensão sagrada, como já vimos, é a união das duas outras dimensões. Ela é, ao mesmo tempo, restituição da unidade originária e dimensão que se estende a toda atividade humana. A arte, a sensibilidade da beleza, seria a presença simultânea de Deus e do ser humano. No entanto, com isso, Fernandes não afirma que Ser e existência possam coincidir. Isso, como vimos, é impossível. A permanência temporal pertence ao profano, não ao religioso. O que pode coincidir é Deus e a sua experiência, mas, essa última, enquanto Ser e não enquanto ente. Até porque, quando eles coincidem, não há mais experiência.

\section{Uma ética da compaixão}

Talvez uma das conclusões mais importantes da Filosofia de Fernandes, que gostaria de destacar neste artigo, consista na afirmação de uma ética do ser-com-o-outro, uma ética da compaixão, entendida pelo filósofo enquanto co-sentimento.

A confusão do Ser com a existência seria, para Fernandes, uma espécie de "pecado original", a origem do mal. Esse "pecado" teria como bases ideias que para ele são absurdas, como a consciência de si (autorreferência) e a temporalidade. Ainda do trabalho inédito Deus - a experiência do ser humanos: "O que a mente chama de 'tempo' não passa de uma ilusão: se até mesmo os 'sujeitos das mudanças' mudassem (fossem 'impermanentes'), não haveria nada fixo que pudesse mudar, só haveria instantes, e o instante é fora do tempo, é eterno."

Achar que somos em algum sentido permanentes, que a permanência pode estar na existência faz com que busquemos um sentido para as coisas e nos identifiquemos com esse buscar. Como não podemos ser o que pensamos, jamais nos conheceremos. Daí nasce a angústia: uma confusão entre Ser e existir. O 'problema do mal', como o intitula Fernandes, não está em haver existência. A existência, enquanto aquilo que não-é, é o contraste necessário ao Ser que possibilita as experiências. O 'problema do mal' está na possibilidade de que, entre essas experiências, algumas delas pensem que são

5 Do artigo Deus: a experiência do ser humano, publicado postumamente na presente edição da Revista $\mathrm{O}$ que nos faz pensar PUC-Rio. 
permanentes ao longo do tempo. Essas experiências reflexivas geram a identidade do eu consigo mesmo e sua consequente diferenciação do outro. Ou seja, elas geram a fronteira entre nós. Assim, Fernandes pode concluir: eu não tenho experiências, pois o eu é fruto de um determinado tipo de experiência. A essas experiências, Sergio denomina metaforicamente de "pecadoras" (mas não há ninguém que peque, já que o próprio eu é fruto do 'pecado'). Estes seriam os 'agoras infernais', agoras de substanciação das identificações ao longo do tempo, e que, com isso, negam os outros agoras únicos em função da impressão que causam de que estamos presos nesse agora. Esse seria o 'erro'. Mas quando o 'erro' é reconhecido como 'erro', nos distinguimos dele. O 'erro' é então aquilo que aparece, pois não está em harmonia. O que verdadeiramente É não aparece, pois não tem contraste suficiente para aparecer. É nesse sentido que a verdade não poderia ser entendida por um sujeito, pois quando há verdade, não há mais ninguém para entendê-la. Esta verdade, que não é jamais a verdade do âmbito da representação, precisaria ser compreendida. $\mathrm{Na}$ compreensão, não haveria mais separação entre sujeito e objeto, só haveria Ser e não mais a fórmula: 'ser + existência = experiência'.

Segundo Fernandes, o problema do 'erro' estaria diretamente relacionado com a questão do medo. É o medo que nos mantém na existência. E o medo fundamental é justamente aquele de perder aquilo que não somos. Esse medo nos mantém como o mesmo, ou seja, diz de nós que somos dois. Esse seria, em máximo grau, o medo fundamental da morte, de se perder, deixar de ser ego, sujeito. Mas o Ser não poderia morrer, pois nunca veio a ser. É nesse sentido que, para permanecermos na existência, enquanto ego, como os mesmos ao longo do tempo, abrimos mão de "sermos tudo". E, no entanto, não nos sobra nada, pois essa existência é, por assim dizer, nadificada, não podemos mesmo jamais Ser enquanto existimos. Não podemos ter acesso ao nosso sujeito, não podemos nos conhecer, estamos perdidos em um ponto cego. Quando nos colocamos na existência, alucinamos, por assim dizer, que não somos e, assim, o Ser (divino e humano) fica ocultado. Nas palavras de Fernandes:

Deus não pode estar onde eu também não estiver e vice-versa. De algum modo coincidimos. Deus está onde estamos. (Está onde nos pôs. Nós é que nunca O pomos onde nós estamos.) Nós é que pensávamos estar onde Ele não estava. (FERNANDES, 2001, p.192)

Não compreender a natureza da mente seria ser assujeitado por ela, isto é, o mal, enquanto a ausência de espírito. A libertação disso seria o que Sergio chamou a presença de espírito, isto é, a presença do Ser no existir. Em termos 
práticos, isso significa transitar entre os vários papéis que desempenhamos sem nos identificarmos rigidamente com nenhuma máscara, com nenhuma representação. Esta seria ainda a condição básica da compaixão. A compaixão se distingue da piedade porque não é uma atitude de um sujeito para com um objeto, ela é uma quebra na estrutura egóica e na dualidade sujeito-objeto, que nos permite sentir o mesmo que um outro, ultrapassando o ego e suas dualidades, por isso a compaixão seria, para Fernandes, a pura presença do Ser no existir. Deus, assim, se esconderia no outro e se revelaria no próximo, pela compaixão. A compaixão é, portanto, apresentada como a presença do reino da Deus na Terra, isto é, do Ser no existir.

A condição de possibilidade da compaixão é o "morrer para si mesmo", ou seja, a compreensão da principal de todas as máscaras: a máscara do ego. Compreender o ego é desidentificar-se dele, usá-lo como máscara apenas quando necessário, e desmascarar-se dele toda vez que precisamos desempenhar outro papel, usar outra máscara. A máscara do ego torna-se assim uma Face que muda de acordo com as circunstâncias, face ao Outro, por exemplo, que havemos de compreender como o Próximo. ${ }^{6}$

O fortalecimento do individualismo, esta atomização crescente que vivemos, esta cegueira ao outro, este ódio generalizado ao estrangeiro, a competição desenfreada, constituem hoje o império do mal na existência. O mal, para Fernandes, seria justamente a identificação objetal: pensar que somos o que pensamos, quando precisamente somos ali onde não pensamos, fora do tempo.

\section{Conclusão}

Como ocorre com todo grande pensador, a Filosofia de Sergio Fernandes possui múltiplas influências: Kant; Hegel; o Romantismo Alemão; as Filosofias Orientais, e também várias relações possíveis com outros filósofos também influenciados pelas mesmas influências que Fernandes sofreu, dentre os quais podemos destacar: Nietzsche (a quem Sergio gostava de dizer que nunca tinha lido), Schopenhauer e Wittgenstein. A produção e reflexões são coletivas, "as mentes se relacionam intimamente", nos diria Fernandes. Mas

6 Idem, Ibidem 
mais importante que isso é a originalidade que sua Filosofia carrega, um verdadeiro sistema como não se produzem mais nos dias atuais, com uma Ontologia, uma Ética, uma Estética, uma Antropologia Filosófica e uma Filosofia da Religião próprias. Aqui procurei ressaltar os aspectos que foram mais importantes na minha formação, tanto acadêmica quanto pessoal, particularmente a questão da autorreferência compreendida como limite da representação, o que ainda hoje ocupa um papel central nas minhas pesquisas, reflexões e, mesmo, conduta no mundo. Como muitos outros ao longo da História, o pensamento de Fernandes e sua produção filosófica não foram devidamente reconhecidos enquanto ele estava vivo. Apesar disso, ele mostrou que ainda é possível filosofar, e que não precisa ser em alemão, pois mesmo com todas as dificuldades que o fazer filosófico enfrenta, sua influência não deixou de ser potente. Gostaria de concluir dizendo mais uma vez: trata-se de um filósofo contemporâneo, brasileiro e extremamente atual. Que sua Filosofia possa ser resgatada, conservada e divulgada pelo valor que ela possui.

\section{Referências}

FERNANDES, S. L. de C. Filosofia e Consciência: Uma investigação ontológica da consciência. Rio de Janeiro: Ed. Areté, 1995.

FERNANDES, Sergio L. de C. . "O Ser Humano como Experiência Divina: Esboço de uma Teoria em Filosofia da Religião" Crítica (UEL), Londrina, PR, v. 6, n.22/Jan.-Ma, pp. 181-212, 2001.

FERNANDES, S. L. de C. Ser Humano: Um ensaio em Antropologia Filosófica. Rio de Janeiro: Mukharajj, 2005.

FERNANDES, S. L. de C. O ser humano como experiência divina: um esbôç̧o de uma teoria em filosofia da religião. Rio de Janeiro: Mukharajj, no prelo.

WITTGENSTEIN, L. Tractatus logico-philosophicus (TLP) Tradução, apresentação, estudo introdutório: Luiz Henrique Lopes dos Santos. Introdução: Bertrand Russel. São Paulo: Editora da Universidade de São Paulo, 1993.

WITTGENSTEIN, L. Da Certeza (DC) Trad.: Maria Elisa Costa. Lisboa: Edições 70, s/data. 